\section{Giant pulmonary artery aneurysm caused by sibutramine-associated pulmonary arterial hypertension: First case in the literature}

\author{
Barkın Kültürsay (D), Berhan Keskin (D), Ali Karagöz (D), Özgür Yaşar Akbal (D), \\ Cihangir Kaymaz (D)
}

Department of Cardiology, University of Health Sciences, Koşuyolu Heart Training and Research Hospital; İstanbul-Turkey

\section{Introduction}

Pulmonary arterial aneurysm (PAA) is a rare and possibly life-threatening abnormality of the pulmonary vasculature. Pulmonary arterial hypertension (PAH) is an important cause of PAA (1). Anorectic agents, such as aminorex, fenfluramine, and benfluorex, have been associated with PAH (2). Unlike those medications, sibutramine has been well tolerated and widely used as an appetite suppressant until it was withdrawn from the market in 2010 owing to its cardiovascular side effects (3). In this report, we present the first case of a patient with sibutramine-associated PAH complicated with massive PAA.

\section{Case Report}

A 40-year-old woman presented to our clinic with syncope, progressive dyspnea, and recurrent palpitations. She had no previous medical history and was an active smoker of 20 packyears. There was no cardiovascular disease in her family history. She stated that she had been taking sibutramine as an appetite suppressant during 2008-2010 and her symptoms commenced after the administration of sibutramine. Physical examination revealed a systolic murmur heard over the left sternal border, hepatomegaly, mild ascites, and pretibial edema. Her saturation was $91 \%$ in room air, Electrocardiography showed sinus rhythm with right axis deviation and right ventricular strain pattern. Routine laboratory workup was normal, and connective tissue disease markers and human immunodeficiency virus (HIV) serology results were negative.

Transthoracic echocardiography showed massive PAA compressing the left heart chambers (Fig. 1a and 1b, Videos 1 and 2), hypertrophied right ventricle, dilated right atrium, and flattening of the interventricular septum. Right ventricular systolic functions were normal, tricuspid regurgitation was severe, and estimated pulmonary artery (PA) systolic pressure was $84 \mathrm{mmHg}$. No left-sided valvular disease or shunts were observed.

Pulmonary computed tomography (CT) angiography confirmed aneurysmal dilatation of the main PA, left and right Pas, and several lobar branches (Fig. 2a-2c). No signs of thrombus or parenchymal disease were observed. There was no congenital anomaly present in the CT.

Heart catheterization showed precapillary pulmonary hypertension with mean PA pressure (PAP) of $50 \mathrm{~mm} \mathrm{Hg}$ and pulmonary vascular resistance of 6.8 Woods units. As the diagnosis of $\mathrm{PAH}$ was established, the patient was started on PAH-specific pharmacotherapy and was offered surgery for the aneurysm.

\section{Discussion}

PAA is a rare entity in pulmonary vascular diseases. Its definition varies among authors. Some authors consider any dilatation of the PA beyond its normal limit $(27 \mathrm{~mm}$ in woman and $29 \mathrm{~mm}$ in men) as an aneurysm, whereas others consider any case with PA diameter $\geq 40 \mathrm{~mm}$ as PAA (4). Along with congenital heart disease, PAH is an important cause of PAA (1).
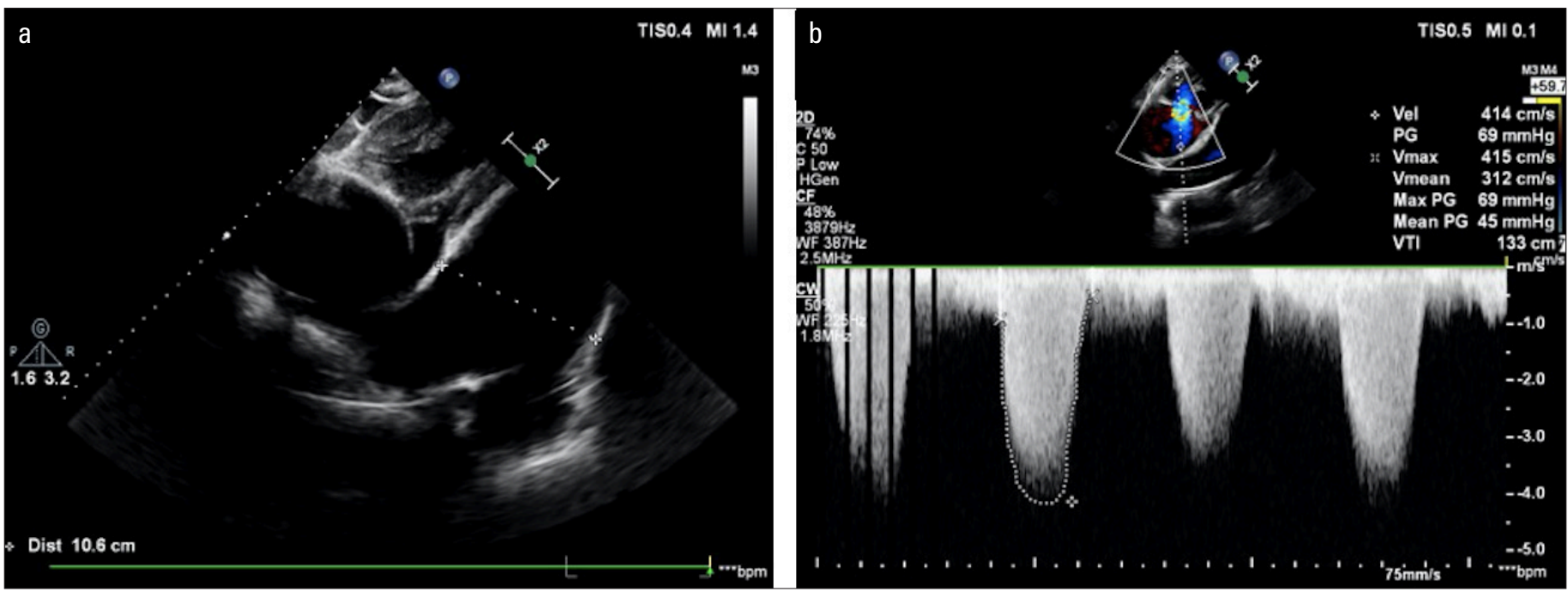

Figure 1. (a) Subcostal transthoracic echocardiography view showing pulmonary artery aneurysm compressing the left heart chambers. (b) Tricuspid regurgitation and estimated pulmonary arterial pressure 

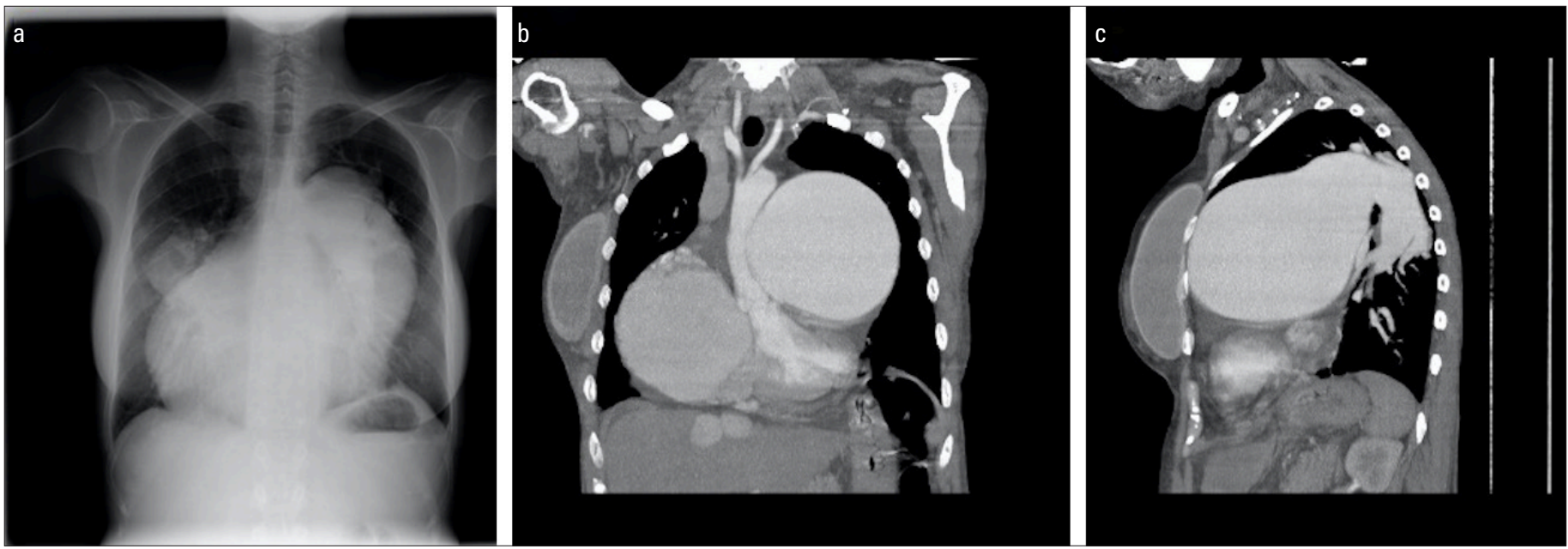

Figure 2. (a) Chest X-ray showing a bulging mass in the left hemithorax. (b) Coronal view of computed tomography (CT) demonstrating giant pulmonary artery aneurysm with a diameter of $10 \mathrm{~cm}$. (c) Sagittal view of the aneurysm

PAH is a progressive cardiopulmonary disease characterized by elevated pulmonary vascular resistance and PAP. In the classification of the European Society of Cardiology, PAH is defined as Group 1 and can be idiopathic, heritable, drug- and toxininduced, or associated with clinical conditions, including HIV infection, connective tissue disease, portal hypertension, and congenital heart disease (5).

Recognition of drug-induced PAH started with the first epidemic of pulmonary hypertension in 1967 in Europe caused by aminorex, which is a central nervous system stimulant used for weight loss (6). Later, other appetite-suppressant drugs, including fenfluramine, benfluorex, and amphetamine derivatives, were associated with an increased risk of PAH development (2). The serotonin pathway has been implicated in anorexigensassociated pulmonary vascular disease (7).

Sibutramine, a serotonin and noradrenaline reuptake inhibitor originally developed as an antidepressant, was approved for weight reduction by the Food and Drug Administration in 1997. It has since been widely used for weight loss with relatively better metabolic improvements and fewer side effects than those of other anorexigenic agents (8). Its effect on PAP was assessed noninvasively, and no difference in PAP was found before and after treatment with sibutramine (9). It was withdrawn from the United States and Europe market in 2010 because of the increased risk of nonfatal myocardial infarction and nonfatal stroke (3). Sibutramine has not been associated with any pulmonary hypertension case per the literature search. To the best of our knowledge, our case is the first one.

In our case, we thoroughly investigated our patient and excluded other causes of pulmonary hypertension, such as left heart disease, lung disease, and chronic thromboembolic disease. Because the patient clearly described symptoms beginning after sibutramine use, we proceeded through our ultimate diagnosis, which was drug-induced PAH. Unlike aortic aneurysms, there is no clear consensus on PAA treatment strategy and surgical indications. Options include conservative observation, treatment of underlying disease, or surgery (1). In cases of
PAA with a diameter $\geq 5.5 \mathrm{~cm}$ and accompanied by $\mathrm{PAH}$, aneurysm surgery or heart-lung transplantation remains the treatment of choice (1).

\section{Conclusion}

PAA is a rare and possibly life-threatening abnormality of the pulmonary vascular system, and PAH is one of the important causes of PAA. Drug-induced PAH remains a diagnostic challenge. Most anorexigenic medications are associated with PAH. Sibutramine, which has not been associated with pulmonary vascular disease previously, can cause PAH as represented in our case. Thus, physicians should investigate any anorexigenic drug exposure, particularly sibutramine, in every case of pulmonary hypertension.

Informed consent: Written informed consent to publication was obtained from the patient.

Video 1. Giant pulmonary artery aneurysm compressing the left heart chambers

Video 2. Doppler evaluation and severe tricuspid regurgitation

\section{References}

1. Kreibich M, Siepe M, Kroll J, Höhn R, Grohmann J, Beyersdorf F. Aneurysms of the pulmonary artery. Circulation 2015; 131: 310-6. [Crossref]

2. Garg L, Akbar G, Agrawal S, Agarwal M, Khaddour L, Handa R, et al. Drug-induced pulmonary arterial hypertension: a review. Heart Fail Rev 2017; 22: 289-97. [Crossref]

3. Krentz AJ, Fujioka K, Hompesch M. Evolution of pharmacological obesity treatments: focus on adverse side-effect profiles. Diabetes Obes Metab 2016; 18: 558-70. [Crossref]

4. Gupta M, Agrawal A, lakovou A, Cohen S, Shah R, Talwar A. Pulmonary artery aneurysm: a review. Pulm Circ 2020; 10: 2045894020908780. [Crossref] 
5. Galiè N, Humbert M, Vachiery JL, Gibbs S, Lang I, Torbicki A, et al.; ESC Scientific Document Group. 2015 ESC/ERS Guidelines for the diagnosis and treatment of pulmonary hypertension: The Joint Task Force for the Diagnosis and Treatment of Pulmonary Hypertension of the European Society of Cardiology (ESC) and the European Respiratory Society (ERS): Endorsed by: Association for European Paediatric and Congenital Cardiology (AEPC), International Society for Heart and Lung Transplantation (ISHLT). Eur Heart J 2016; 37: 67-119. [Crossref]

6. Gurtner HP. Aminorex and pulmonary hypertension. A review. Cor Vasa 1985; 27: 160-71.

7. Bazan IS, Fares WH. Review of the Ongoing Story of Appetite Suppressants, Serotonin Pathway, and Pulmonary Vascular Disease. Am J Cardiol 2016; 117: 1691-6. [Crossref]
8. Scheen AJ. Cardiovascular risk-benefit profile of sibutramine. Am J Cardiovasc Drugs 2010; 10: 321-34. [Crossref]

9. Guven A, Koksal N, Cetinkaya A, Sokmen G, Ozdemir R. Effects of the sibutramine therapy on pulmonary artery pressure in obese patients. Diabetes Obes Metab 2004; 6: 50-5. [Crossref]

Address for Correspondence: Dr. Barkın Kültürsay,

Koşuyolu Yüksek Ihtisas Eğitim ve Araştırma Hastanesi, Kardiyoloji Kliniği, Istanbul-Türkiye

Phone: +90 5546383037

E-mail: bkultursay@gmail.com

(C) Copyright 2021 by Turkish Society of Cardiology Available online at www.anatoljcardiol.com DOI:10.5152/AnatolJCardiol.2021.64166 